\title{
What is the role of routine ultrasonography performed in the first trimester of low-risk pregnancy?
}

\author{
Qual É o PAPEL da ULTRASSONOGRAFIA de ROTINA REALIZADA NO PRIMEIRO TRIMESTRE
}

EM GESTAÇÕES DE BAIXO RISCO?

\author{
Authorship: Brazilian Medical Association (AMB) \\ Participants: Ricardo Simões ${ }^{1}$, Wanderley M. Bernardo ${ }^{1}$ \\ Final draft: April 2016
}

1Programa Diretrizes, Brazilian Medical Association (AMB)

The Guidelines Project, an initiative of the Brazilian Medical Association, aims to combine information from the medical field in order to standardize procedures to assist the reasoning and decision-making of doctors.

The information provided through this project must be assessed and criticized by the physician responsible for the conduct that will be adopted, depending on the conditions and the clinical status of each patient.

\section{STRUCTURED QUESTION}

The clinical question is structured according to the PICO components: P (Patient), I (Intervention), C (Comparison), O (Outcome).

- P: Low-risk pregnancy (first trimester)

- I: Ultrasonography

- C:

- O:

\section{BASES OF SCIENTIFIC DATA CONSULTED}

The scientific database searched was PubMed-Medline. A manual search of the references of reviews (narrative or systematic) was also performed.

\section{Strategies fOR SEARCh OF EVIDENCE}

\author{
PubMed-Medline \\ Strategy: (Pregnancy Trimester, First OR First Trimester OR Phases, \\ Early Placental OR Pregnancy Trimesters, First OR First Pregnancy \\ Trimester OR Pregnancies, First Trimester) AND (Ultrasonography \\ OR Echography OR Ultrasonic Diagnoses). N=838
}

\section{Results of the eVidence Selected}

The evidence was assessed according to the Oxford classification, which establishes the strength of the evidence based on the study design chosen.

\section{Discussion}

Ultrasonography allows the evaluation of the fetal morphology and biometric data, the examination of the fetal anatomy and the detection of major congenital defects, as well as subtle markers that signal the possibility of chromosomal abnormalities and genetic syndromes. Until a few years ago, early ultrasonography aimed to identify the number of fetuses, to verify chorionicity in the case of multiple pregnancies, and to date the pregnancy. In recent years, however, with improved technology providing images with better resolution, as well as access to ultrasound examinations for a greater number of pregnant women, early identification of embryo-fetal defects has been favored. The objective of this review was to evaluate the contribution of ultrasound performed in the first trimester (between weeks 11 and 14) in low-risk pregnancies (except in the situations listed in Table 1). Aspects assessed include determining gestational age, characterizing multiple pregnancies, and evaluating the fetal anatomy. With regard to the diagnosis of malformations, it is possible to detect structural abnormalities and genetic syndromes.

Verification of gestational age

Calculating gestational age continues to be an extremely important measure in prenatal follow-up and reproductive research, allowing appropriate assessment of fetal development. Inaccuracies are inherent to the ultrasound imaging method and often observed, especially measurement errors and the biological variability of the fetus. Numerous studies have revealed that the estimated gestational age obtained from ultrasound proved to be superior to that obtained using the date of the first day of the last menstrual cycle (LMP), predicting even more safely the probable date of delivery. ${ }^{2-4}(\mathbf{B})$ This fact stems mainly from the difficulty many women have in inform- 
TABLE 1 Risk factors that may indicate referral to high-risk prenatal care.

Factors related to previous conditions

Heart diseases, severe lung diseases (including bronchial asthma), severe kidney diseases (such as chronic renal failure and transplant patients), endocrine diseases (particularly diabetes mellitus, hypothyroidism, and hyperthyroidism), hematological disorders (including sickle cell disease and thalassemia), chronic hypertension and/or patients treated with antihypertensive medication (PA > $140 / 90 \mathrm{mmHg}$ before gestational age of 20 weeks), neurological diseases (such as epilepsy), psychiatric disorders requiring monitoring (psychosis, severe depression, etc.), autoimmune diseases (systemic lupus erythematosus, other collagenoses), maternal genetic diseases, history of deep venous thrombosis or pulmonary embolism, gynecological disorders (uterine malformation, myomatosis, adnexal tumors, and others), patients with infectious diseases such as hepatitis, toxoplasmosis, HIV infection, tertiary syphilis (USG with fetal malformation), and other STDs (condyloma), Hansen's disease, tuberculosis, licit or illicit drug addiction, any clinical pathology that requires specialized monitoring.

\section{Factors related to previous reproductive history}

Intrauterine or perinatal death in previous gestation, especially if the cause is unknown; previous history of hypertensive gestational disease with poor obstetric and/or perinatal outcome (premature termination of pregnancy, intrauterine fetal death, Hellp syndrome, eclampsia, maternal ICU admission); repeated abortion; infertility.

Factors related to the current pregnancy

Restriction of intrauterine growth; polyhydramnios or oligohydramnios; twin pregnancy; fetal malformations or fetal arrhythmia; hypertensive disorders of gestation (pre-existing chronic hypertension, gestational or transient hypertension); recurrent urinary tract infection or two or more episodes of pyelonephritis; severe or unresponsive anemia after 30-60 days of treatment with ferrous sulfate; patients with infectious diseases such as hepatitis, toxoplasmosis, HIV infection, tertiary syphilis (USG with fetal malformation), and other STDs (condyloma); infections such as rubella and cytomegalovirus acquired in the current gestation; laboratory evidence of proteinuria; gestational diabetes mellitus; severe maternal malnutrition; morbid obesity or low weight.

Adapted from: Ministério da Saúde, 2012.'

ing the exact date of the last menstrual period or the misinterpretation of genital bleeding related to egg implantation as menstrual bleeding. In addition, the convention of a 14-day interval between menstruation and ovulation may render gestational age calculations inaccurate, especially for women with irregular menstrual cycles. ${ }^{5}$ (B)

Finally, studies have consistently shown that the use of the date of the last menstrual period for the purpose of estimating gestational age is related to a greater frequency of a later due date compared to that which is verified when this estimate is obtained from the early ultrasound (10 to $12 \%$ versus $4 \%$, respectively). ${ }^{3,6}$ (B)

\section{Early detection of a multiple gestation}

It is known that multiple pregnancies are associated with increased perinatal morbidity and mortality compared to single fetus pregnancies. Therefore, early identification of multiple pregnancies and determination of the type of placenta play an important role in the risk stratification and monitoring of twin pregnancies, contributing significantly to a better prognosis. Observational studies designed to analyze the accuracy of ultrasonography performed during the first trimester in multiple pregnancies to predict chorionicity consistently found high values of sensitivity, specificity, positive and negative predictive values compared to those observed from ultrasonographies performed in the second trimester. ${ }^{7,8}(\mathbf{B})$ Thus, ultrasound, especially when performed by the end of week 14 , is a reliable tool for determining the number of chorions in a twin pregnancy.

\section{Evaluation of fetal morphology}

First trimester ultrasound, performed between week 11 and week 14 of pregnancy, aims to track chromosomal abnormalities, genetic syndromes and other fetal malformations. This imaging method is well-established for the screening of aneuploidies. In 2008, Kagan et al. showed that the increase in cutaneous thickness present in individuals with Down syndrome could be seen in the first trimester (from 11 to 13 weeks plus 6 days). They also verified that increased nuchal translucency (thickness above the $95^{\text {th }}$ percentile for gestational age), when associated with maternal age and biochemical tests such as maternal serum levels of beta-hCG free fraction and pregnancy-associated plasma protein (PAPP-A) provided a detection rate of $90 \%$ of cases of trisomy 21 with a false-positive rate of $3 \% .^{9}$ (B) Even in the absence of chromosomal abnormality, fetuses exhibiting increased nuchal translucency have an increased risk of intrauterine death and structural abnormalities, especially cardiac. ${ }^{10}(\mathbf{B})$

Some abnormalities like anencephaly are almost always detected. However, others such as myelomeningocele or microcephaly may be difficult or impossible to identify. Numerous studies analyzing the performance of first trimester ultrasonography to detect fetal abnormalities found that the findings were either incidental during screening for aneuploidy or were detected after careful 
examination of euploid fetuses due to increased nuchal translucency. ${ }^{11}$ (D) In this regard, the findings of the related studies do not reflect the true performance of first-trimester ultrasonography for the screening of nonchromosomal abnormalities. A multicenter clinical trial conducted by Saltvedt et al. was designed to analyze the sensitivity of morphological ultrasound examinations performed during the first and second trimesters to identify fetal malformations. To do so, they randomized more than 39,000 pregnant women to perform a single ultrasound during pregnancy, between weeks 12 and 14, or between weeks 15 and 22 . The authors found a detection rate of $38 \%$ for the first group compared to $47 \%$ for the second, but the difference was not significant. ${ }^{12}$ (B)

\section{ReCOMmendation}

Routine ultrasonography performed in the first trimester of low-risk pregnancies allows a better calculation of gestational age, preventing diagnosis of a later due date and consequent iatrogenic preterm delivery. It also allows the characterization of the number of fetuses and chorionicity. ${ }^{13}$ (A). This imaging modality also contributes to the identification of aneuploidy and, increasingly, to the diagnosis of structural anomalies.

\section{RefEREnCES}

1. BRASIL. Ministério da Saúde. Atenção ao pré-natal de baixo risco. Brasília: Ministério da Saúde, 2012. (Cadernos de Atenção Básica, 32)

2. Savitz DA, Terry JW Jr, Dole N, Thorp JM Jr, Siega-Riz AM, Herring AH Comparison of pregnancy dating by last menstrual period, ultrasound scanning, and their combination. Am J Obstet Gynecol. 2002; 187(6):1660-6.

3. Hoffman CS, Messer LC, Mendola P, Savitz DA, Herring AH, Hartmann KE. Comparison of gestational age at birth based on last menstrual period and ultrasound during the first trimester. Paediatr Perinat Epidemiol. 2008; 22(6):587-96.

4. Taipale P, Hiilesmaa V. Predicting delivery date by ultrasound and last menstrual period in early gestation. Obstet Gynecol. 2001; 97(2):189-94.

5. Nguyen TH, Larsen T, Engholm G, Møller H. Evaluation of ultrasoundestimated date of delivery in 17,450 spontaneous singleton births: do we need to modify Naegele's rule? Ultrasound Obstet Gynecol. 1999; 14(1):23-8.

6. Tunón K, Eik-Nes SH, Grøttum P. A comparison between ultrasound and a reliable last menstrual period as predictors of the day of delivery in 15,000 examinations. Ultrasound Obstet Gynecol. 1996; 8(3):178-85.

7. Lee YM, Cleary-Goldman J, Thaker HM, Simpson LL. Antenatal sonographic prediction of twin chorionicity. Am J Obstet Gynecol. 2006; 195(3):863-7.

8. Menon DK. A retrospective study of the accuracy of sonographic chorionicity determination in twin pregnancies. Twin Res Hum Genet. 2005; 8(3):259-61.

9. Kagan KO, Wright D, Valencia C, Maiz N, Nicolaides KH. Screening for trisomies 21, 18 and 13 by maternal age, fetal nuchal translucency, fetal heart rate, free beta-hCG and pregnancy-associated plasma protein-A. Hum Reprod. 2008; 23(9):1968-75.

10. Souka AP, Snijders RJ, Novakov A, Soares W, Nicolaides KH. Defects and syndromes in chromosomally normal fetuses with increased nuchal translucency thickness at 10-14 weeks of gestation. Ultrasound Obstet Gynecol. 1998; 11(6):391-400.

11. Souka AP, Von Kaisenberg CS, Hyett JA, Sonek JD, Nicolaides KH. Increased nuchal translucency with normal karyotype. Am J Obstet Gynecol. 2005; 192(4):1005-21.

12. Saltvedt S, Almström H, Kublickas M, Valentin L, Grunewald C. Detection of malformations in chromosomally normal fetuses by routine ultrasound at 12 or 18 weeks of gestation - a randomised controlled trial in 39,572 pregnancies. BJOG. 2006; 113(6):664-74.

13. Whitworth M, Bricker L, Mullan C. Ultrasound for fetal assessment in early pregnancy. Cochrane Database Syst Rev. 2015; (7):CD007058. 